\title{
Sorption of polyfluoroalkyl surfactants on surface soils: Effect of molecular structures, soil properties, and solution chemistry
}

\section{Supporting Information}

\author{
Sandra Mejia-Avendaño†, Yue Zhi†, Bei Yan, Jinxia Liu* \\ Department of Civil Engineering, McGill University, Montréal, Québec, H3A 0C3, Canada
}

$\dagger$ The authors contributed equally to the manuscript.

*Corresponding author. Tel: +1 514398 7938; fax: +1 514398 7361;e-mail address:

jinxia.liu@mcgill.ca 


\section{Table of content}

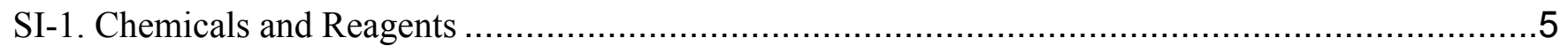

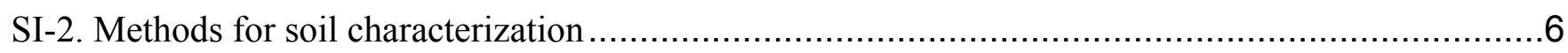

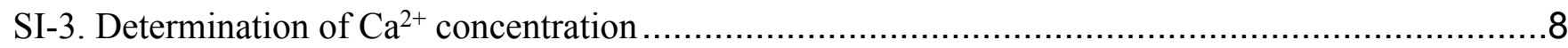

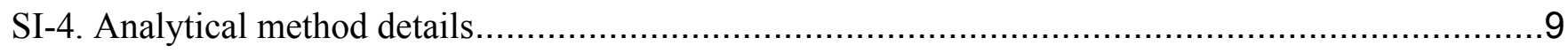

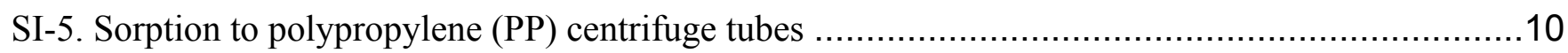

SI-6. Calculation of soil-water partitioning using aqueous loss approach ................................11

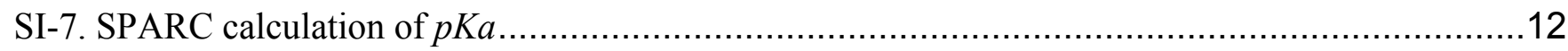

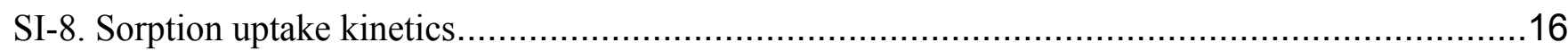

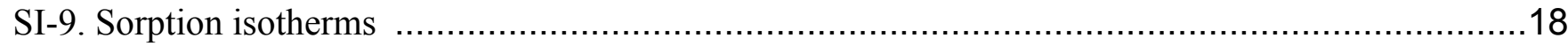

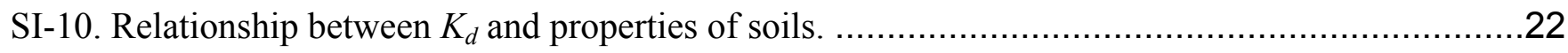

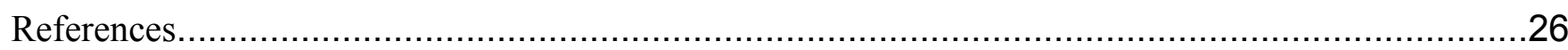




\section{List of Figures}

Figure S1. Relationship between measured cation exchange capacity (CEC) or anion exchange capacity (AEC) and $\mathrm{pH}$ of the water-soil slurries.

Figure S2. Concentration change of PFASs in PP tubes in 68-h mixing. Error bars stand for the standard deviation of triplicate samples. 10

Figure S3. Speciation plot of 6:2 FTAB 12

Figure S4. Speciation plot of PFOAB 13

Figure S5. Speciation plot of PFOSB .14

Figure S6. Speciation plot of PFOAAmS .15

Figure S7. Uptake kinetics of nine PFASs by the loam soil (Soil \#4). Lines represent the pseudosecond-order model fits of the experimental measurements. Error bars stand for the standard deviation of triplicate samples. .17

Figure S8. Sorption isotherms of polyfluoroalkyl acids and polyfluoroalkyl substances in five soils.

Figure S9. (Logrithmetic version of Figure 2) Interpolated values of distribution coefficient $\left(K_{d}\right)$ of 9 representative PFASs in 5 soils. $K_{d}=\frac{C_{s}}{C_{a q}}=K_{F} \times C_{a q}^{n-1}$; where Freundlich sorption coefficient $\left(K_{F}\right)$, and linearity of isotherms (n) were derived from twenty-point isotherms using nonlinear regression. Values of $K_{F}$ and n (with 95\% confidence interval) are listed in Table S7. $C_{a q}$ is the concentration in the aqueous phase at apparent equilibrium $(\mathrm{nM})$, values of $K_{d}$ were calculated at equilibrium aqueous concentration $\mathrm{C}_{\mathrm{aq}}=10 \mathrm{nM}, 100 \mathrm{nM}$, and $1000 \mathrm{nM}$. 20

Figure S10. Relationship between $K_{d}$ of (A) perfluoroalkyl acids, (B) fluorotelomer sulfonates, and (C) newly-identified PFASs (i.e., 6:2 FTAB, PFOAB, PFOSB and PFOAAmS) and organic carbon fraction $\left(f_{c}\right)$ of soil. $K_{d}$ was calculated at $\mathrm{C}_{\mathrm{aq}}=100 \mathrm{nM}$.

Figure S11. Relationship between $K_{d}$ of (A) perfluoroalkyl acids, (B) fluorotelomer sulfonates, and (C) newly-identified PFASs (i.e., 6:2 FTAB, PFOAB, PFOSB and PFOAAmS) and soil clay fraction $\left(f_{\text {clay }}\right)$. $K_{d}$ was calculated at $\mathrm{C}_{\mathrm{aq}}=100 \mathrm{nM}$. .24

Figure S12. Relationship between $K_{d}$ of PFASs and soil cation exchange capacity (CEC), the left figures, and anion exchange capacity (AEC), the right figures. $K_{d}$ was calculated at $\mathrm{C}_{\mathrm{aq}}=100 \mathrm{nM} .25$ 


\section{List of Tables}

Table S1. The total aqueous concentration of $\mathrm{Ca}^{2+}(\mathrm{M})$ of the soil-water solution at equilibrium as measured by ICP-OES.

Table S2. Kinetic parameters of the pseudo-second-order model of sorption...........................17

Table S3. Summary of calculated fit parameters for Freundlich isotherms of PFASs in five soils.19

Table S4. Interpolated values of organic carbon-normalized distribution coefficients coefficient $\left(K_{o c} \pm\right.$ $S D, L / \mathrm{kg}_{o c}$ ) of 9 representative PFASs in 5 soils. $K_{o c}=K_{d} / f_{o c}$, where $f_{o c}$ is the organic carbon fraction. 20

Table S5. Results of Pearson correlation between the adsorption distribution coefficient $\left(K_{d}\right)$ of PFASs and organic carbon fraction $\left(f_{o c}\right)$, clay fraction $\left(f_{\text {clay }}\right)$, cation exchange capacity (CEC), and anion exchange capacity (AEC) 


\section{SI-1. Chemicals and Reagents}

Perfluorooctanoic acid (PFOA), perfluorodecanoic acid (PFDA), potassium perfluorooctane sulfonate (PFOS), and sodium azide were obtained from Sigma Aldrich (St. Louis, MO). 6:2 and 8:2 fluorotelomer sulfonic acids (6:2 and 8:2 FTSAs) were purchased from SynQuest Laboratories (Alachua, FL). Perfluorooctaneamide ammonium salt [PFOAAmS, $\mathrm{F}\left(\mathrm{CF}_{2}\right)_{7} \mathrm{CONH}\left(\mathrm{CH}_{2}\right)_{3} \mathrm{~N}^{+}\left(\mathrm{CH}_{3}\right)_{3}$ ], perfluorooctane amidoalkyl betaine [PFOAB, $\left.\mathrm{F}\left(\mathrm{CF}_{2}\right)_{7} \mathrm{CONH}\left(\mathrm{CH}_{2}\right)_{3} \mathrm{~N}^{+}\left(\mathrm{CH}_{3}\right)_{2} \mathrm{CH}_{2} \mathrm{COOH}\right]$, and perfluorooctane sulfonamidoalkyl betaine [PFOAB, $\left.\mathrm{F}\left(\mathrm{CF}_{2}\right)_{8} \mathrm{SO}_{2} \mathrm{NH}\left(\mathrm{CH}_{2}\right)_{3} \mathrm{~N}^{+}\left(\mathrm{CH}_{3}\right)_{2} \mathrm{CH}_{2} \mathrm{COOH}\right]$ were customsynthesized at the Beijing Surfactant Institute (Beijing, China). The description of chemical synthesis methods can be found in our previous study. ${ }^{1}$ 6:2 fluorotelomer sulfonamidoalkyl betaine [6:2 FTAB, $\left.\mathrm{F}\left(\mathrm{CF}_{2}\right)_{6} \mathrm{CH}_{2} \mathrm{CH}_{2} \mathrm{SO}_{2} \mathrm{NH}\left(\mathrm{CH}_{2}\right)_{3} \mathrm{~N}^{+}\left(\mathrm{CH}_{3}\right)_{2} \mathrm{CH}_{2} \mathrm{COOH}\right]$ was obtained from Shanghai Kingpont Industrial Company, Ltd. (Shanghai, China).

Isotope-labeled internal standards (IS), including MPFOA, MPFDA, MPFOS, M6:2 FTSA, and M8:2 FTSA, were purchased from Wellington Laboratories (Guelph, ON, Canada). HPLC-grade acetonitrile (ACN), LCMS-grade water and acetic acid (HAc), calcium chloride dehydrate, as well as certified sodium hydroxide $(10 \mathrm{~N})$ and certified hydrochloric acid $(8 \mathrm{~N})$, were purchased from Fisher Scientific (Ottawa, ON, Canada). 


\section{SI-2. Methods for soil characterization}

Organic carbon content $\left(f_{o c}\right)$ was determined at a commercial lab using high-temperature combustion. Cation exchange capacity (CEC) and anion exchange capacity (AEC) were determined by Sumner and Miller's method (Methods of Soil Analysis, Part 3, Chapter 41, p 1243-1244). ${ }^{2}$ Briefly, $5 \pm 0.01 \mathrm{~g}$ of dried and ground soil was added into $50-\mathrm{mL}$ pre-weighed centrifuge tubes. $50 \mathrm{~mL}$ of $1 \mathrm{M} \mathrm{KCl}$ solution was then added. The mixture was shaken at $150 \mathrm{rpm}$ for $1 \mathrm{~h}$ using a horizontal shaker, then centrifuged for $10 \mathrm{~min}$ at $5000 \mathrm{rpm}$. The supernatant was decanted and discarded as completely as possible. The residue soil was washed five times with $50 \mathrm{~mL}$ of $0.01 \mathrm{M} \mathrm{KCl}$, shaken for $4 \mathrm{~h}$, and centrifuged for $10 \mathrm{~min}$ at $5000 \mathrm{rpm}$. The supernatant $\mathrm{pH}$ was determined and recorded. The final supernatant was centrifuged and decanted but retained for $\mathrm{K}^{+}$and $\mathrm{Cl}^{-}$determination $\left(C_{l}\right)$. The tubes were weighted to obtain the volume $\left(V_{1}\right)$ of the entrained solution in the sediment in order to determine entrained $\mathrm{K}^{+}$and $\mathrm{Cl}^{-}$. It is assumed that the concentrations of the entrained $\mathrm{K}^{+}$and $\mathrm{Cl}^{-}$were equal to those of the final washing solution. The final sediment was washed four times with $20 \mathrm{~mL}$ of $0.5 \mathrm{M} \mathrm{NaNO}_{3}$ to displace the adsorbed $\mathrm{K}^{+}$and $\mathrm{Cl}^{-}$, and then centrifuged, the exchanging solution was decanted into a $100 \mathrm{~mL}$ brown glass bottle $\left(V_{2}\right)$ that was brought to volume and subsequently analyzed for $\mathrm{K}^{+}$and $\mathrm{Cl}^{-}\left(C_{2}\right)$. All the experiments were performed in triplicate. The concentration of $\mathrm{K}^{+}$and $\mathrm{Cl}^{-}$were determined by the atomic absorption spectroscopy and ionic chromatography, respectively.

Values of CEC and AEC (meq/100 g) are calculated as eq.1 and 2.

$$
\begin{aligned}
& \mathrm{CEC}=\frac{0.1 \times\left(C_{2} V_{2}-C_{1} V_{1}\right)}{39 W} \\
& \mathrm{AEC}=\frac{0.1 \times\left(C_{2} V_{2}-C_{1} V_{1}\right)}{35.5 W}
\end{aligned}
$$

where $C_{1}$ is the concentration of $\mathrm{K}^{+}$or $\mathrm{Cl}^{-}$in final washing solution of $0.01 \mathrm{M} \mathrm{KCl}, C_{2}$ is the concentration of $\mathrm{K}^{+}$or $\mathrm{Cl}^{-}$in the displacing solution of $0.5 \mathrm{M} \mathrm{NaNO}_{3}, V_{l}$ and $V_{2}$ denote the volume $(\mathrm{mL})$ of the solution entrained in sediments after the final washing of $0.01 \mathrm{M} \mathrm{KCl}$ and the total volume $(\mathrm{mL})$ of the displacing solution of $0.5 \mathrm{M} \mathrm{NaNO}_{3}$, respectively. $W$ is the dried sample weight in gram. 

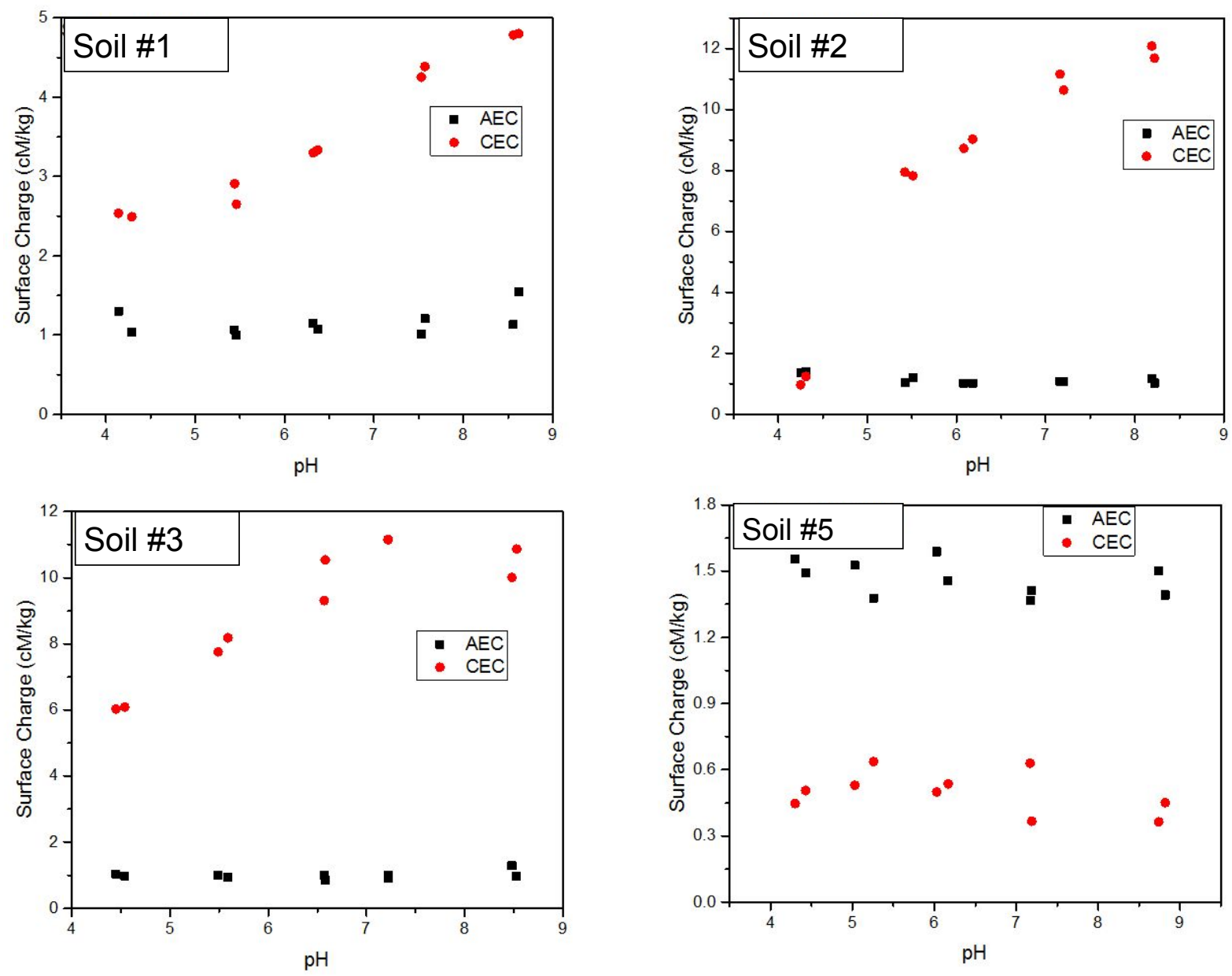

Figure S1. Relationship between measured cation exchange capacity (CEC) or anion exchange capacity (AEC) and $\mathrm{pH}$ of the water-soil slurries. 


\section{SI-3. Determination of $\mathrm{Ca}^{2+}$ concentration}

To investigate the effect of $\mathrm{Ca}^{2+}$, equilibrium experiments were performed with five initial concentrations of $\mathrm{Ca}^{2+}$ ranging from 0.1 to $50 \mathrm{mM}$ with Soil \# 3 and Soil \#4. At equilibrium, tubes were centrifuged, the supernatant was retrieved and diluted 50-500 times in deionized water with $2 \%(\mathrm{v} / \mathrm{v}) \mathrm{HNO}_{3}$. The diluted acidified samples were analyzed by Inductively Coupled Plasma - Optical Emission Spectroscopy (ICPOES, Thermo ICap Duo 6500), recording at $317.933 \mathrm{~nm}$.

Table S1. The total aqueous concentration of $\mathrm{Ca}^{2+}(\mathrm{M})$ of the soil-water solution at equilibrium as measured by ICP-OES

\begin{tabular}{|c|c|c|}
\hline$\#$ & Soil \#3 & Soil \#4 \\
\hline 1 & $1.00 \times 10^{-3}$ & $1.73 \times 10^{-3}$ \\
\hline 2 & $1.97 \times 10^{-3}$ & $2.77 \times 10^{-3}$ \\
\hline 3 & $8.15 \times 10^{-3}$ & $9.11 \times 10^{-3}$ \\
\hline 4 & $2.26 \times 10^{-2}$ & $2.16 \times 10^{-2}$ \\
\hline 5 & $4.71 \times 10^{-2}$ & $4.75 \times 10^{-2}$ \\
\hline
\end{tabular}




\section{SI-4. Analytical method details}

Instrument

Ionization

Acquisition mode

Delay column

Analytical column

Column Temperature

Mobile phases

Gradient Profile

Injection volume
Shimadzu Nexera UHPLC coupled to an AB Sciex 5500 QTrap mass spectrometer

Positive and negative electrospray

Multiple reaction monitoring (MRM)

Kinetex EVO C18, $5 \mu \mathrm{m}, 50 \times 3.1 \mathrm{~mm}$

Agilent Zorbax SB-C8, $3.5 \mu \mathrm{m}, 100 \times 2.1 \mathrm{~mm}$

$40^{\circ} \mathrm{C}$

A: $0.15 \%$ acetic acid in LCMS water

B: $0.15 \%$ acetic acid in acetonitrile

$\underline{\text { Time }(\min )} \quad \underline{\text { Percentage B }}$

$0.5 \quad 10$

$5.0 \quad 90$

$6.0 \quad 90$

$6.1 \quad 10$

6.5 Stop

$5 \mu \mathrm{L}$

Quantified compounds

\begin{tabular}{|c|c|c|c|c|}
\hline Analyte & $\mathrm{RT}(\min )$ & $\begin{array}{l}\text { MRM } \\
\text { transition }\end{array}$ & IS & $\begin{array}{l}\text { IS MRM } \\
\text { transiton }\end{array}$ \\
\hline 6:2 FTSA & & $-427>80$ & M6:2FTSA & $429>81$ \\
\hline $8: 2$ FTSA & & $-527>80$ & M8:2FTSA & $529>81$ \\
\hline PFOA & & $-413>369$ & MPFOA & $417>372$ \\
\hline PFDA & & $-513>469$ & MPFDA & $515>470$ \\
\hline PFOS & & $-499>80$ & MPFOS & $503>80$ \\
\hline $6: 2$ FTAB & & $-569>446$ & M6:2FTSA & $429>81$ \\
\hline PFOAB & & $-555>378$ & MPFOA & $417>372$ \\
\hline PFOSB & & $-641>538$ & MPFOS & $503>80$ \\
\hline PFOAAmS & & $+513>454$ & MPFOA & $417>372$ \\
\hline
\end{tabular}




\section{SI-5. Sorption to polypropylene (PP) centrifuge tubes}

Sorption of PFASs to PP tubes was tested. Briefly, $0.01 \mathrm{M}$ of $\mathrm{KCl}$ was prepared in HPLC-grade water. 15 $\mathrm{mL}$ of the $\mathrm{KCl}$ solution was transferred to a PP tube and spiked with PFASs stock solution. Tubes were vortexed for $30 \mathrm{~s}$ and the concentrations were measured immediately. The starting concentration was shown in blue bars in Figure S1. All the tubes were shaken for $68 \mathrm{~h}$ on a platform shaker, concentrations were measured again, and reported in clear bars in Figure S1.

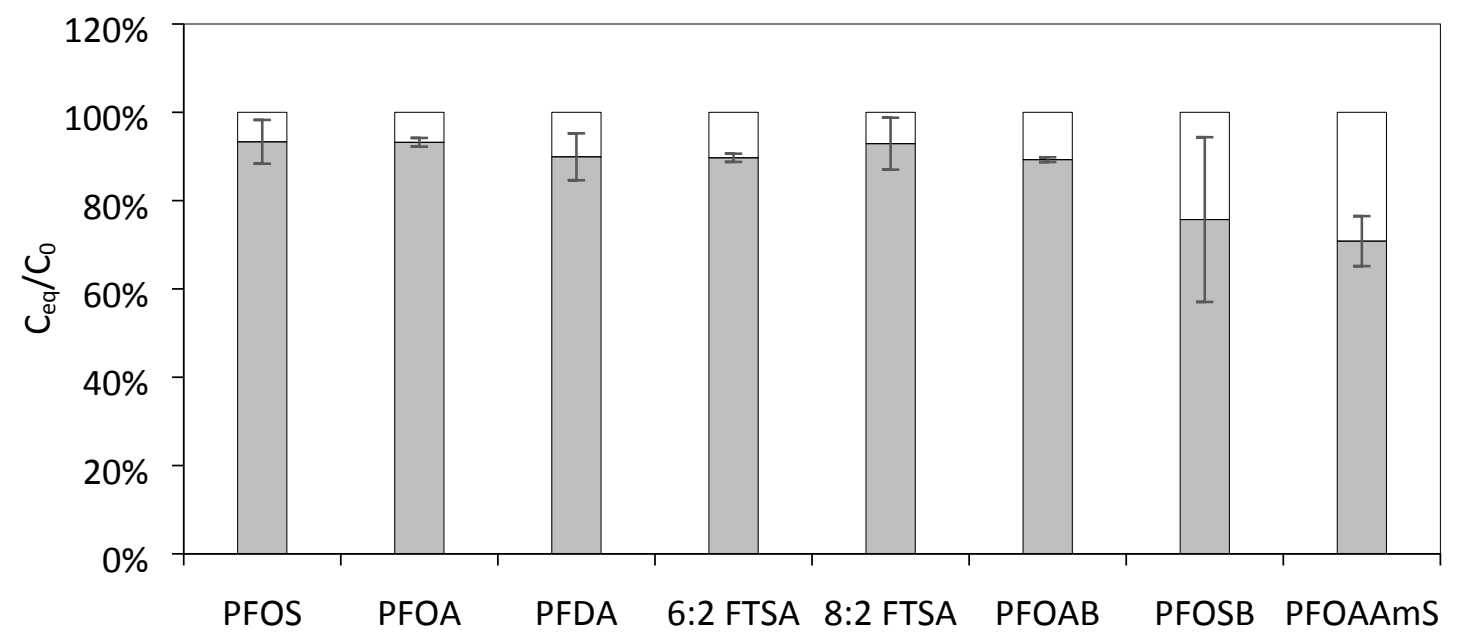

Figure S2. Concentration change of PFASs in PP tubes in 68-h mixing. Error bars stand for the standard deviation of triplicate samples. 


\section{SI-6. Calculation of soil-water partitioning using aqueous loss approach}

According to the following definitions

$\begin{array}{llc}C & \text { Concentration at time } t & \frac{\mathrm{nmol}}{\mathrm{kg}} \\ C_{a q} & \text { Concentration in aqueous phase } & \mathrm{nM} \\ C_{s} & \text { Concentration in soil } & \frac{\mathrm{nmol}}{\mathrm{kg}} \\ V_{a q} & \text { Volume of water } & \mathrm{L} \\ \sigma_{v} & \text { Concentration on the polystyrene vial } & \frac{\mathrm{nmol}}{\mathrm{m}^{2}} \\ A_{V} & \text { Surface area of vial } & \mathrm{m}^{2} \\ K_{V} & \text { Equilibrium distribution coefficient between the } & \frac{\mathrm{L}}{\mathrm{m}^{2}} \\ & \text { vial and water, } K_{V}=\frac{\sigma_{v}}{r_{a v}} C_{a q} & \frac{\mathrm{m}^{2}}{\mathrm{~L}} \\ & \text { Surface area to volume ratio of vial, } r_{a v}=\frac{A_{V}}{V_{A}} & \mathrm{~kg} / \mathrm{L} \\ r_{s w} & \text { Solid water ratio } & \mathrm{L} / \mathrm{kg} \\ K_{d} & \text { Equilibrium distribution coefficient between water } & \end{array}$

For analytes with substantial losses $(>10 \%)$ in controls, concentration in the solid phase were corrected by an equilibrium loss approach reported in Higgins and Luthy $2006 .{ }^{3}$ It is assuming equilibrium between all three phases present: soil, water, and the PP vial. If equilibrium is assumed, the fraction remaining in the aqueous phase, $f w$, in the controls is given by:

$$
f_{w}=\frac{C_{a q} V_{a q}}{C_{a q} V_{a q}+\sigma_{v} A_{V}}=\frac{1}{1+\frac{\sigma_{v} A_{V}}{C_{a q} V_{a q}}}=\frac{1}{1+r_{a v} K_{V}}
$$

If a soil is included in the system, eq. 11 becomes:

$$
f_{w}=\frac{C_{a q} V_{a q}}{C_{a q} V_{a q}+\sigma_{v} A_{V}}=\frac{1}{1+r_{s w} K_{d}+r_{a v} K_{V}}
$$

The concentration on the soil, $\mathrm{C}_{\mathrm{s}}$, was then calculated from the measured $\mathrm{C}_{\mathrm{aq}}$ and $f_{w}$ and the estimated $r_{a v} K_{V}$. 


\section{SI-7. SPARC calculation of $p K a$}

1) 6:2 FTAB speciation

SMILES: $\mathrm{O}=\mathrm{S}(\mathrm{CCC}(\mathrm{F})(\mathrm{F}) \mathrm{C}(\mathrm{F})(\mathrm{F}) \mathrm{C}(\mathrm{F})(\mathrm{F}) \mathrm{C}(\mathrm{F})(\mathrm{F}) \mathrm{C}(\mathrm{F})(\mathrm{F}) \mathrm{C}(\mathrm{F})(\mathrm{F}) \mathrm{F})(\mathrm{NCCC}[\mathrm{N}+](\mathrm{C})(\mathrm{C}) \mathrm{CC}(\mathrm{O})=\mathrm{O})=\mathrm{O}$

\section{Species:}

S1<smiles>C[N+](C)(CCCNS(=O)(=O)CCC(F)(F)C(F)(F)C(F)(F)C(F)(F)C(F)(F)C(F)(F)F)CC(=O)O</smiles>

S2

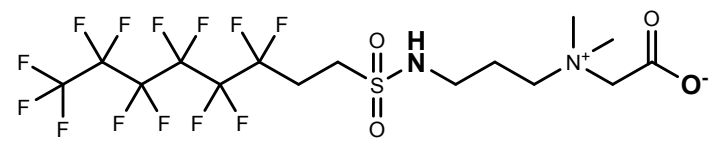

S3

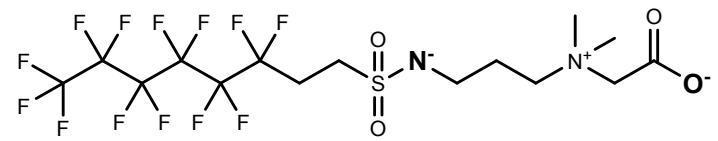

S4
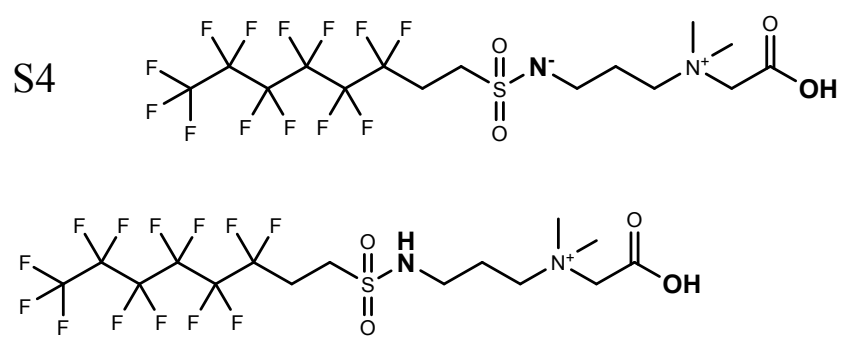

$\rightleftharpoons$

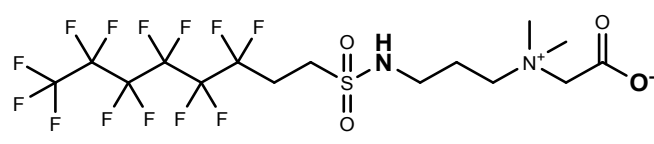

pKa 2.26<smiles>C[N+](C)(CCCN[S@](=O)(O)NCCCC(F)(F)C(F)(F)C(F)(F)C(F)(F)C(F)(F)C(F)(F)C(F)(F)F)CC(=O)[O-]</smiles>

pKa 11.12

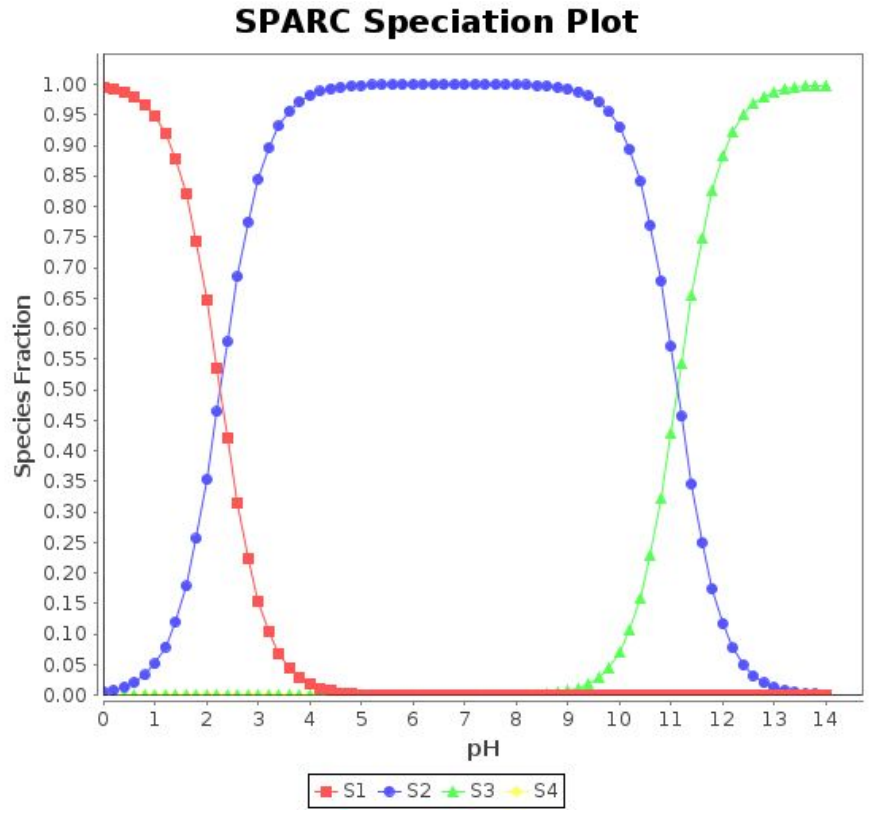

Figure S3. Speciation plot of 6:2 FTAB 


\section{2) PFOAB speciation}

SMILES: FC(F)(F)C(F)(F)C(F)(F)C(F)(F)C(F)(F)C(F)(F)C(F)(F)C(NCCC $[N+](C)(C) C C(O)=O)=O$ Species:

S1<smiles>C[N+](C)(CCCNC(=O)C(F)(F)C(F)(F)C(F)(F)C(F)(F)C(F)(F)C(F)(F)C(F)(F)F)CC(=O)O</smiles>

S2<smiles>C[N+](C)(CCCNC(=O)C(F)(F)C(F)(F)C(F)(F)C(F)(F)C(F)(F)C(F)(F)C(F)(F)F)CC(=O)O</smiles>

S3<smiles>C[N+](C)(CCCNC(=O)C(F)(F)C(F)(F)C(F)(F)C(F)(F)C(F)(F)C(F)(F)C(F)(F)F)CC(=O)O</smiles>

S4<smiles>C[N+](C)(CCCNC(=O)C(F)(F)C(F)(F)C(F)(F)C(F)(F)C(F)(F)C(F)(F)C(F)(F)F)CC(=O)O</smiles><smiles>CN(CCCNC(=O)C(F)(F)C(F)(F)C(F)(F)C(F)(F)C(F)(F)C(F)(F)C(F)(F)F)C(=O)C(F)(F)C(F)(F)C(F)(F)C(F)(F)C(F)(F)C(F)(F)C(F)(F)C(F)(F)C(F)(F)C(F)(F)C(F)(F)F</smiles>

pKa 2.25<smiles>CN(CCCNC(=O)C(=O)N(C)CCCNC(=O)C(F)(F)C(F)(F)C(F)(F)C(F)(F)C(F)(F)C(F)(F)C(F)(F)C(F)(F)C(F)(F)C(F)(F)C(F)(F)C(F)(F)C(F)(F)C(F)(F)F)CC(=O)O</smiles>
pKa 7.79

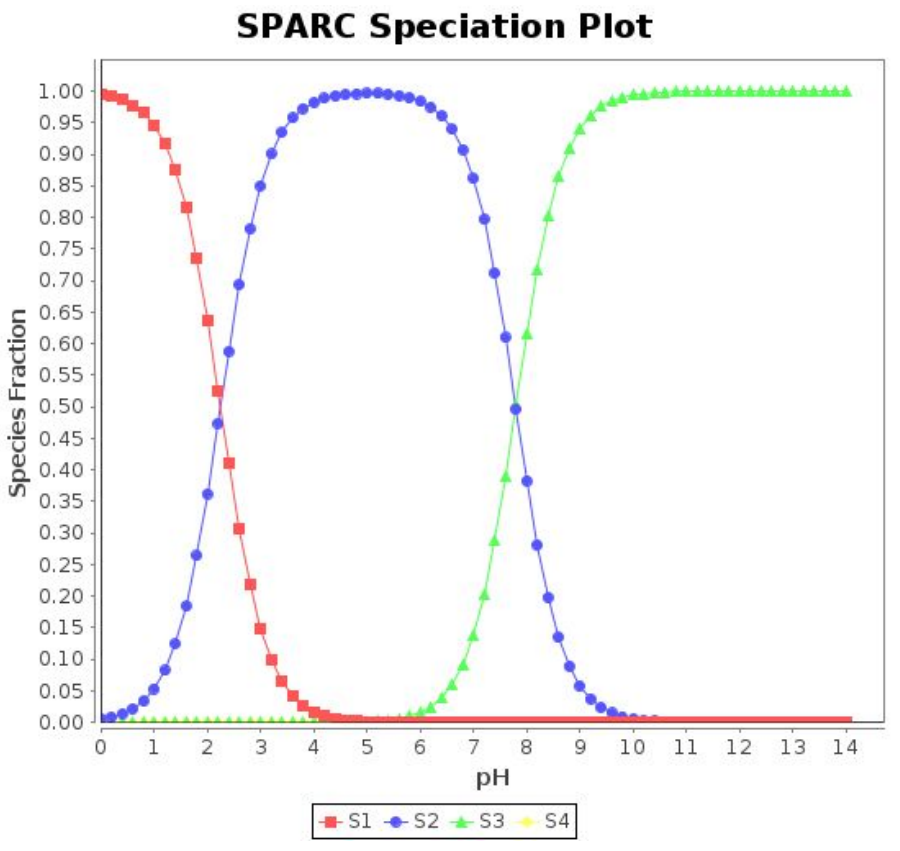

Figure S4. Speciation plot of PFOAB 


\section{3) PFOSB speciation}

SMILES:

$\mathrm{O}=\mathrm{S}(\mathrm{C}(\mathrm{F})(\mathrm{F}) \mathrm{C}(\mathrm{F})(\mathrm{F}) \mathrm{C}(\mathrm{F})(\mathrm{F}) \mathrm{C}(\mathrm{F})(\mathrm{F}) \mathrm{C}(\mathrm{F})(\mathrm{F}) \mathrm{C}(\mathrm{F})(\mathrm{F}) \mathrm{C}(\mathrm{F})(\mathrm{F}) \mathrm{C}(\mathrm{F})(\mathrm{F}) \mathrm{F})(\mathrm{NCCC}[\mathrm{N}+](\mathrm{C})(\mathrm{C}) \mathrm{CC}(\mathrm{O})=\mathrm{O})=\mathrm{O}$

\section{Species:}

S1

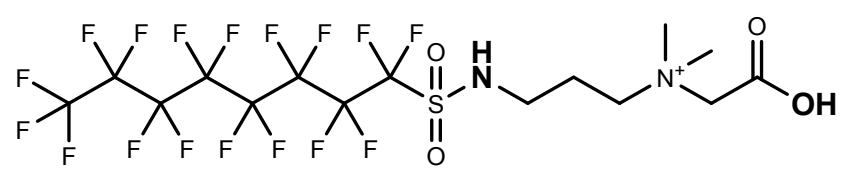

S2

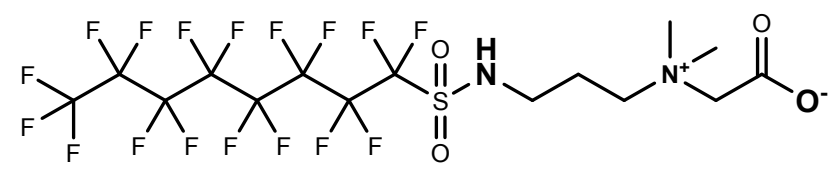

S3

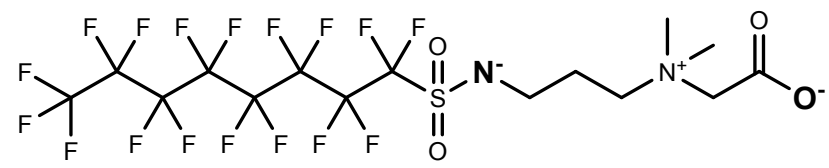

S4
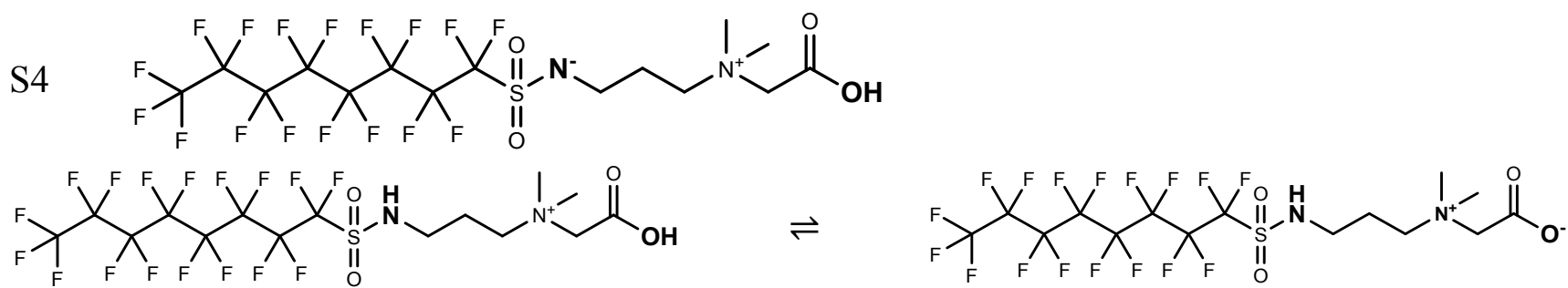

pKa 2.26

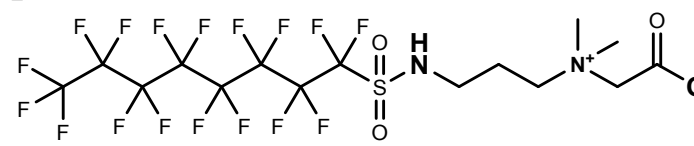<smiles></smiles>

pKa 6.78

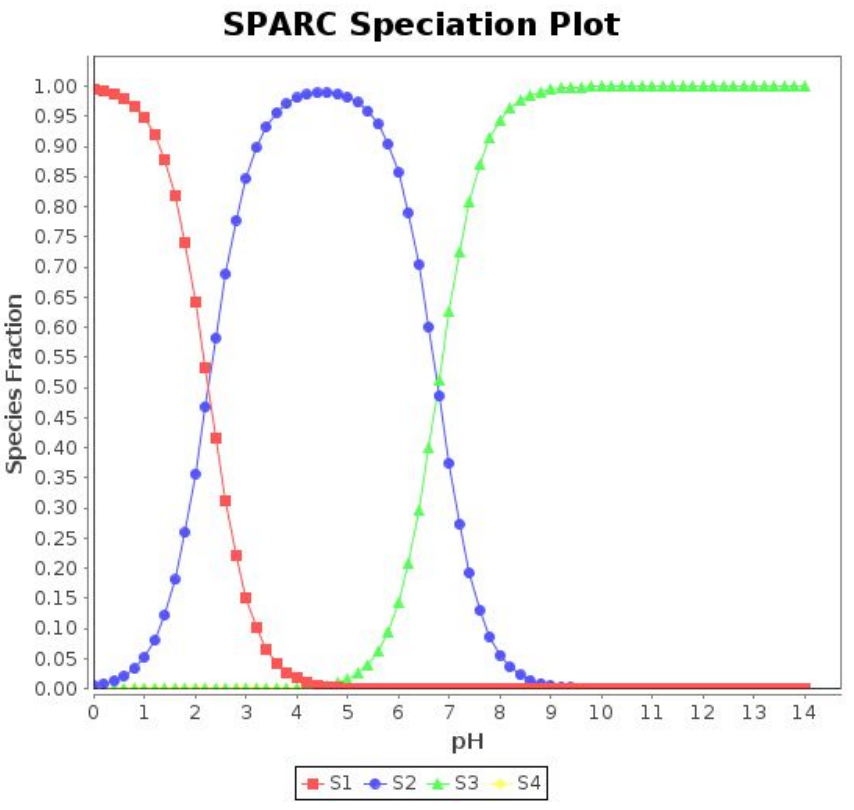

Figure S5. Speciation plot of PFOSB 


\section{4) PFOAAmS speciation}

SMILES:

$\mathrm{FC}(\mathrm{F})(\mathrm{F}) \mathrm{C}(\mathrm{F})(\mathrm{F}) \mathrm{C}(\mathrm{F})(\mathrm{F}) \mathrm{C}(\mathrm{F})(\mathrm{F}) \mathrm{C}(\mathrm{F})(\mathrm{F}) \mathrm{C}(\mathrm{F})(\mathrm{F}) \mathrm{C}(\mathrm{F})(\mathrm{F}) \mathrm{C}(\mathrm{NCCC}[\mathrm{N}+](\mathrm{C})(\mathrm{C}) \mathrm{C})=\mathrm{O}$

\section{Species:}

S1<smiles>C[N+](C)(C)CCCNC(=O)C(F)(F)C(F)(F)C(F)(F)C(F)(F)C(F)(F)C(F)(F)C(F)(F)F</smiles>

S2<smiles>C[N+](C)(C)CCC[N-]C(=O)C(F)(F)C(F)(F)C(F)(F)C(F)(F)C(F)(F)C(F)(F)C(F)(F)F</smiles><smiles>C[N+](C)(C)CCCNC(=O)C(F)(F)C(F)(F)C(F)(F)C(F)(F)C(F)(F)C(F)(F)C(F)(F)F</smiles>

$\rightleftharpoons$<smiles>C[N+](C)(C)CCC[NH2+]C(=O)C(F)(F)C(F)(F)C(F)(F)C(F)(F)C(F)(F)C(F)(F)C(F)(F)F</smiles>

pKa 7.71

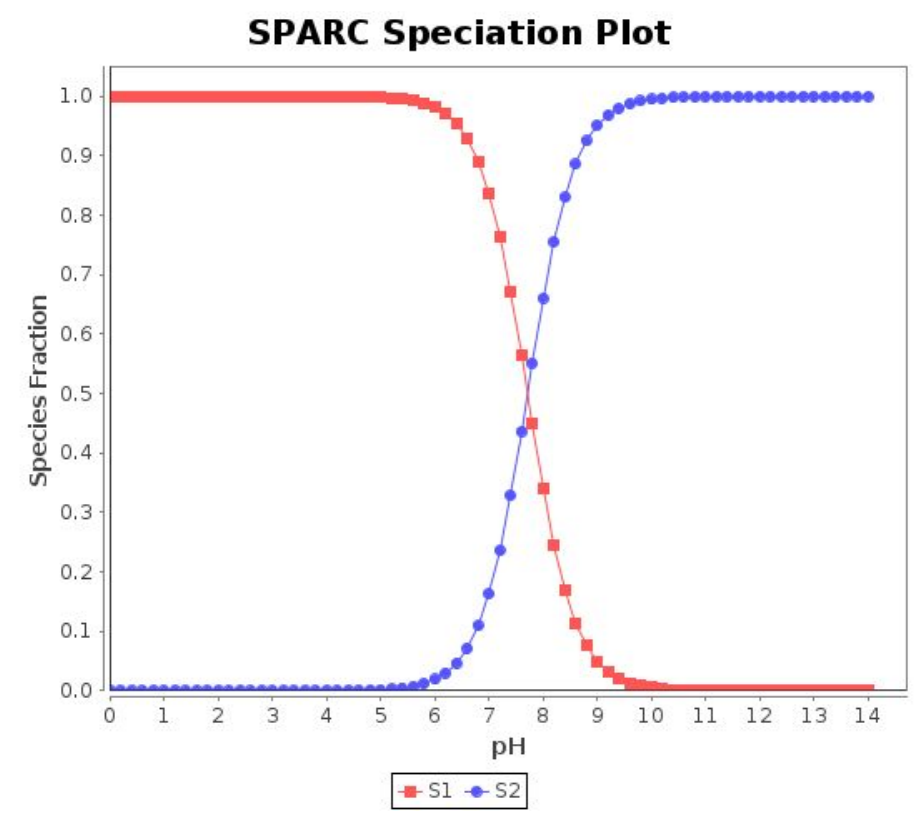

Figure S6. Speciation plot of PFOAAmS 


\section{SI-8. Sorption uptake kinetics}

\section{1) Pseudo-second-order kinetics}

According to the following definitions

$\begin{array}{lll}C & \text { Concentration at time } t & \frac{\mathrm{nmol}}{\mathrm{kg}} \\ C_{e q} & \text { Concentration at equilibrium } & \frac{\mathrm{nmol}}{\mathrm{kg}} \\ t & \text { Time } & \mathrm{h} \\ k & \text { Rate constant } & \frac{\mathrm{nmol}}{\mathrm{k}} \cdot h \\ v_{0} & \text { Initial adsorption rate } & \frac{\mathrm{nmol}}{\mathrm{k}} \cdot h\end{array}$

The uptake rate is given by

$$
\frac{d C}{d t}=k\left(C_{e q}-C\right)^{2}
$$

which is integrated from time 0 to time $t$ and from 0 to $C$ :

$$
\begin{gathered}
\int_{0}^{C} \frac{d C}{\left(C_{e q}-C\right)^{2}}=k \int_{0}^{t} d t \\
C=\frac{k C_{e q}^{2} \cdot t}{1+k C_{e q} \cdot t}=\frac{v_{0} \cdot t}{1+{ }^{v_{0}} / C_{e q} \cdot t}
\end{gathered}
$$

\section{2) Uptake kinetics of nine PFASs by the loam soil}

The sequential sampling of soil/water systems containing PFASs displayed rapid equilibration. Figure S7 shows the sorbed concentration of each surfactant onto the loam soil (Soil 1) at different equilibration times, as well as the kinetic model fits. For every compound, a fast increase of the sorbed concentration was observed in the first 24 hours. The pseudo-second-order kinetic model was used to calculate the time necessary to reach 90 and $99 \%$ of the equilibrium concentration. The equilibration time of anionic surfactants was shorter than that of the non-anionic compounds, and polyfluoroalkyl betaines took the longest to equilibrate (Table S2). The longest equilibration was found to for the sorption of PFOAB by Soil \#4 (65 h). Therefore, all subsequent experiments were shaken for 72 hours to ensure that at least $99 \%$ of equilibrium concentration has been reached. With the same initial concentration $(1 \mu \mathrm{M})$, after 72-hour equilibrium, the sorbed fraction $\left(1-\mathrm{C}_{\mathrm{eq}} / \mathrm{C}_{0}\right)$ follows the order of: PFOAAmS $(+)>\operatorname{PFOSB}(+/-)>$ PFOS(-) $>\operatorname{PFDA}(-)>8: 2$ FTSA $(-)>6: 2 \operatorname{FTAB}(+/-)>\operatorname{PFOAB}(+/-)>\operatorname{PFOA}(-)>6: 2 \operatorname{FTSA}(-)$. 

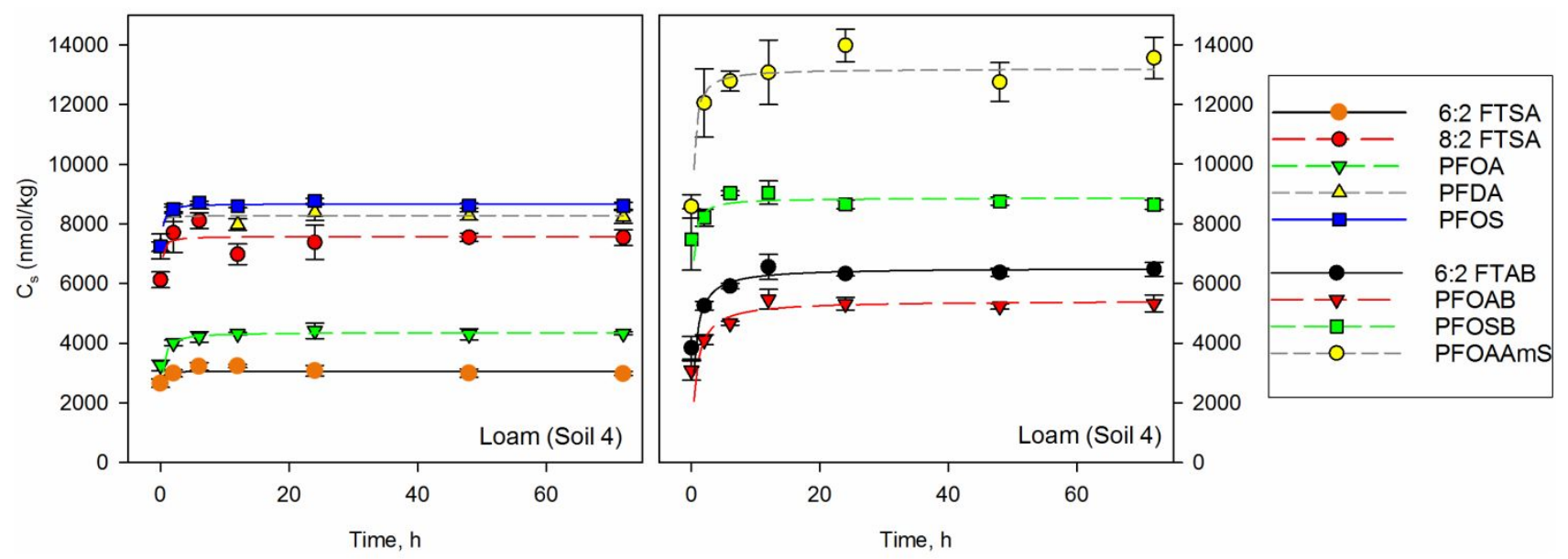

Figure S7. Uptake kinetics of nine PFASs by the loam soil (Soil \#4). Lines represent the pseudosecond-order model fits of the experimental measurements. Error bars stand for the standard deviation of triplicate samples.

\section{3) Kinetic parameters of sorption model}

Kinetic data were fitted to the previously derived equation. Parameters are detailed in Table S2, as well as the calculated time necessary to reach 50, 90 and $99 \%$ of the equilibrium concentration in soil.

Table S2. Kinetic parameters of the pseudo-second-order model of sorption for Soil \#2 and \#4.

\begin{tabular}{|c|c|c|c|c|c|c|c|}
\hline Analyte & Soil & $\frac{\begin{array}{c}C_{e q} \\
\text { nmol }\end{array}}{\frac{k g}{}}$ & $\begin{array}{c}\begin{array}{c}k \\
\text { nmol }\end{array} \\
\frac{k}{h}\end{array}$ & $\begin{array}{c}v_{0} \\
\frac{n m o l}{k} \cdot h\end{array}$ & $\begin{array}{l}t_{0.50} \\
\min \end{array}$ & $\begin{array}{c}t_{0.90} \\
h\end{array}$ & $\begin{array}{c}\boldsymbol{t}_{0.99} \\
\boldsymbol{h}\end{array}$ \\
\hline $6: 2$ FTSA & Loam (Soil \#4) & 3060 & $1.41 \times 10^{-2}$ & $1.32 \times 10^{5}$ & 1.39 & 0.21 & 2.30 \\
\hline $8: 2$ FTSA & Loam (Soil \#4) & 7583 & $3.36 \times 10^{-3}$ & $1.93 \times 10^{5}$ & 2.35 & 0.35 & 3.88 \\
\hline PFOA & Loam (Soil \#4) & 4363 & $1.30 \times 10^{-3}$ & $2.48 \times 10^{4}$ & 10.6 & 1.59 & 17.4 \\
\hline PFDA & Loam (Soil \#4) & 8273 & $1.14 \times 10^{-2}$ & $7.79 \times 10^{5}$ & 0.64 & 0.10 & 1.05 \\
\hline PFOS & Loam (Soil \#4) & 8672 & $3.09 \times 10^{-3}$ & $2.33 \times 10^{5}$ & 2.24 & 0.34 & 3.69 \\
\hline $6: 2$ FTAB & Loam (Soil \#4) & 6522 & $3.17 \times 10^{-4}$ & $1.35 \times 10^{4}$ & 29.0 & 4.35 & 47.8 \\
\hline $6: 2$ FTAB & Clay loam (Soil \#2) & 5431 & $5.96 \times 10^{-4}$ & $1.76 \times 10^{4}$ & 18.5 & 2.78 & 30.6 \\
\hline PFOAB & Loam (Soil \#4) & 5423 & $2.82 \times 10^{-4}$ & $8.28 \times 10^{3}$ & 39.3 & 5.89 & 64.8 \\
\hline PFOAB & Clay loam (Soil \#2) & 3792 & $7.25 \times 10^{-4}$ & $1.04 \times 10^{4}$ & 21.8 & 3.27 & 36.0 \\
\hline PFOSB & Loam (Soil \#4) & 8865 & $9.18 \times 10^{-4}$ & $1.09 \times 10^{3}$ & 7.37 & 1.11 & 12.2 \\
\hline PFOSB & Clay loam (Soil \#2) & 7105 & $7.06 \times 10^{-4}$ & $3.57 \times 10^{4}$ & 12.0 & 1.79 & 19.7 \\
\hline PFOAAmS & Loam (Soil \#4) & 13198 & $5.50 \times 10^{-4}$ & $9.57 \times 10^{4}$ & 8.27 & 1.24 & 13.6 \\
\hline PFOAAmS & Clay loam (Soil \#2) & 15100 & $6.69 \times 10^{-4}$ & $1.53 \times 10^{5}$ & 5.94 & 0.89 & 9.79 \\
\hline
\end{tabular}




\section{SI-9. Sorption isotherms}
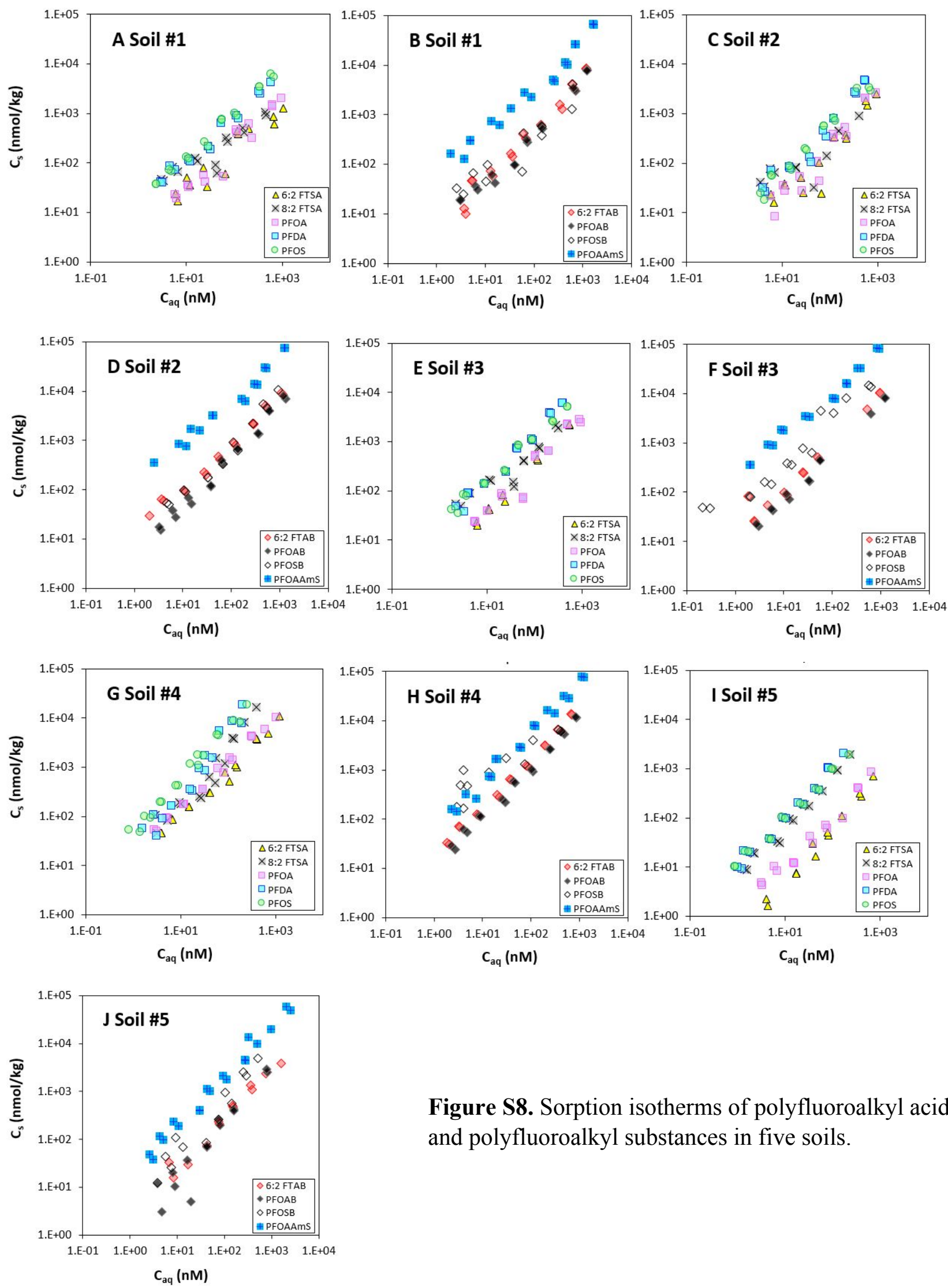

Figure S8. Sorption isotherms of polyfluoroalkyl acids and polyfluoroalkyl substances in five soils. 
Table S3. Summary of calculated fit parameters for Freundlich isotherms of PFASs in five soils.

\begin{tabular}{|c|c|c|c|c|}
\hline & Soil & $\boldsymbol{K}_{F}$ & $n$ & n 95\% CI \\
\hline $6: 2$ FTSA & Soil 1 - Loam & 14.5 & 0.63 & $0.46-0.88^{*}$ \\
\hline 6:2 FTSA & Soil 2 - Clay loam & 1.05 & 1.14 & $0.97-1.36$ \\
\hline 6:2 FTSA & Soil 3 - Silty clay loam & 2.61 & 1.07 & $1.04-1.11^{*}$ \\
\hline $6: 2$ FTSA & Soil 4 - Loam & 5.05 & 1.08 & $0.96-1.21$ \\
\hline $6: 2$ FTSA & Soil 5 - Sandy loam & 0.13 & 1.31 & $1.18-1.46^{*}$ \\
\hline $8: 2$ FTSA & Soil 1 - Loam & 11.9 & 0.72 & $0.60-0.87^{*}$ \\
\hline $8: 2$ FTSA & Soil 2 - Clay loam & 4.83 & 0.87 & $0.69-1.10$ \\
\hline $8: 2$ FTSA & Soil 3 - Silty clay loam & 5.60 & 1.03 & $0.86-1.24$ \\
\hline $8: 2$ FTSA & Soil 4 - Loam & 5.14 & 1.35 & $1.25-1.47^{*}$ \\
\hline $8: 2$ FTSA & Soil 5 - Sandy loam & 3.52 & 1.16 & $1.11-1.21^{*}$ \\
\hline PFOA & Soil 1 - Loam & 5.18 & 0.87 & $0.73-1.05$ \\
\hline PFOA & Soil 2 - Clay loam & 2.78 & 1.02 & $0.84-1.25$ \\
\hline PFOA & Soil 3 - Silty clay loam & 13.9 & 0.78 & $0.63-0.98^{*}$ \\
\hline PFOA & Soil 4 - Loam & 27.9 & 0.86 & $0.79-0.93 *$ \\
\hline PFOA & Soil 5 - Sandy loam & 0.28 & 1.24 & $1.14-1.36^{*}$ \\
\hline PFDA & Soil 1 - Loam & 12.6 & 0.92 & $0.83-1.02$ \\
\hline PFDA & Soil 2 - Clay loam & 2.12 & 1.23 & $1.13-1.33^{*}$ \\
\hline PFDA & Soil 3 - Silty clay loam & 16.2 & 1.01 & $0.90-1.12$ \\
\hline PFDA & Soil 4 - Loam & 39.5 & 1.11 & $0.77-1.68$ \\
\hline PFDA & Soil 5 - Sandy loam & 6.91 & 1.12 & $1.01-1.25^{*}$ \\
\hline PFOS & Soil 1 - Loam & 21.2 & 0.88 & $0.74-1.05$ \\
\hline PFOS & Soil 2 - Clay loam & 29.5 & 0.73 & $0.56-0.96 *$ \\
\hline PFOS & Soil 3 - Silty clay loam & 20.5 & 0.89 & $0.83-0.96 *$ \\
\hline PFOS & Soil 4 - Loam & 46.2 & 1.08 & $0.86-1.37$ \\
\hline PFOS & Soil 5 - Sandy loam & 9.89 & 0.99 & $0.91-1.08$ \\
\hline 6:2 FTAB & Soil 1 - Loam & 0.54 & 1.37 & $1.22-1.54^{*}$ \\
\hline 6:2 FTAB & Soil 2 - Clay loam & 10.3 & 0.97 & $0.88-1.07$ \\
\hline 6:2 FTAB & Soil 3 - Silty clay loam & 2.70 & 1.20 & $1.11-1.30^{*}$ \\
\hline 6:2 FTAB & Soil 4 - Loam & 5.15 & 1.20 & $1.05-1.37^{*}$ \\
\hline 6:2 FTAB & Soil 5 - Sandy loam & 7.77 & 0.85 & $0.77-0.93^{*}$ \\
\hline PFOAB & Soil 1 - Loam & 0.34 & 1.41 & $1.25-1.59^{*}$ \\
\hline PFOAB & Soil 2 - Clay loam & 4.00 & 1.06 & $0.90-1.24$ \\
\hline PFOAB & Soil 3 - Silty clay loam & 3.98 & 1.08 & $0.98-1.19$ \\
\hline PFOAB & Soil 4 - Loam & 4.97 & 1.15 & $1.05-1.25^{*}$ \\
\hline PFOAB & Soil 5 - Sandy loam & 1.45 & 1.12 & $0.97-1.34^{*}$ \\
\hline PFOSB & Soil 1 - Loam & 0.16 & 1.57 & $1.42-1.73^{*}$ \\
\hline PFOSB & Soil 2 - Clay loam & 2.21 & 1.24 & $1.06-1.45^{*}$ \\
\hline PFOSB & Soil 3 - Silty clay loam & 172 & 0.70 & $0.58-0.84^{*}$ \\
\hline PFOSB & Soil 4 - Loam & 215 & 0.56 & $0.43-0.76^{*}$ \\
\hline PFOSB & Soil 5 - Sandy loam & 1.58 & 1.29 & $1.07-1.56^{*}$ \\
\hline
\end{tabular}




\begin{tabular}{|l|l|l|l|l|}
\hline PFOAAmS & Soil 1 - Loam & 6.91 & 1.24 & $\mathbf{1 . 1 4}^{-1.35}$ \\
\hline PFOAAmS & Soil 2 - Clay loam & 24.7 & 1.12 & $\mathbf{1 . 0 3 ~ - ~ 1 . 2 3}^{*}$ \\
\hline PFOAAmS & Soil 3 - Silty clay loam & 73.6 & 1.04 & $0.94-1.14$ \\
\hline PFOAAmS & Soil 4 - Loam & 32.0 & 1.10 & $0.97-1.25$ \\
\hline PFOAAmS & Soil 5 - Sandy loam & 30.7 & 0.96 & $0.79-1.18$ \\
\hline
\end{tabular}

*Note: values of $\mathrm{n}$ significantly differ from linearity (the $95 \%$ confidence interval for $n$ value included $1.0)$

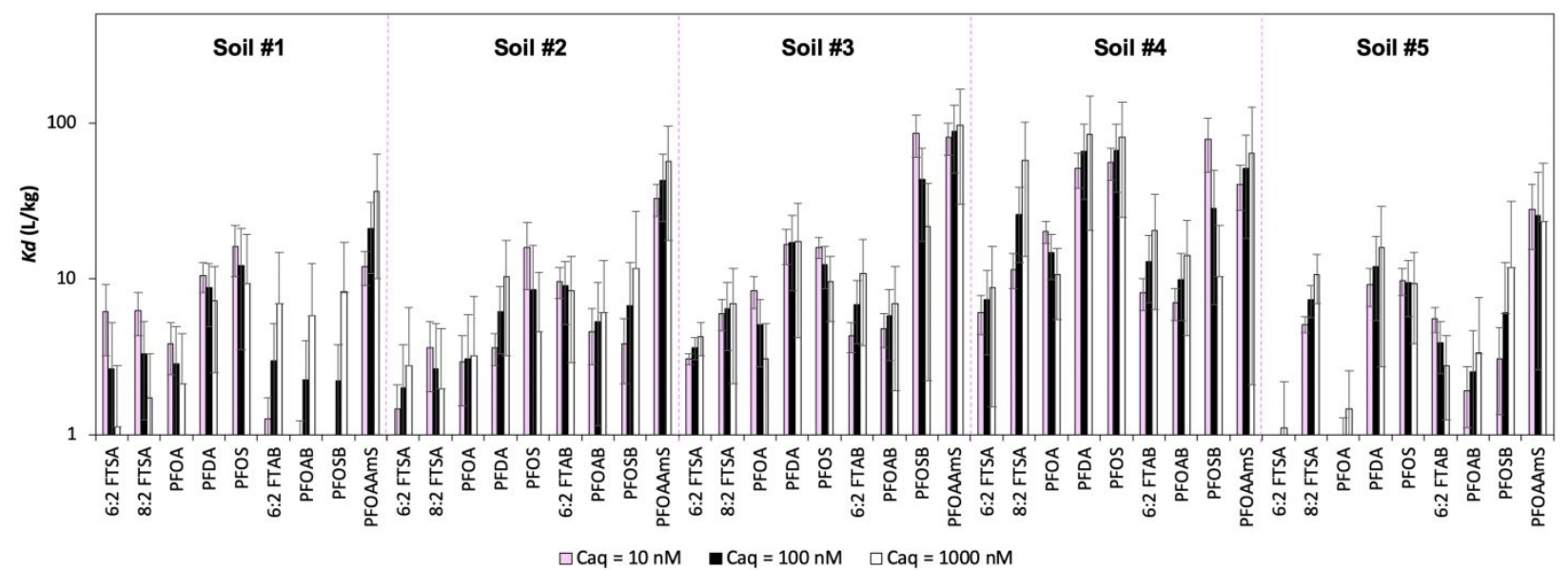

Figure S9. (Logarithmic version of Figure 2) Interpolated values of distribution coefficient $\left(K_{d}\right)$ of 9 representative PFASs in 5 soils. $K_{d}=\frac{C_{s}}{C_{a q}}=K_{F} \times C_{a q}^{n-1}$; where Freundlich sorption coefficient $\left(K_{F}\right)$, and linearity of isotherms (n) were derived from twenty-point isotherms using nonlinear regression. Values of $K_{F}$ and n (with 95\% confidence interval) are listed in Table S7. $C_{a q}$ is the concentration in the aqueous phase at apparent equilibrium $(\mathrm{nM})$, values of $K_{d}$ were calculated at equilibrium aqueous concentration $\mathrm{C}_{\mathrm{aq}}=10 \mathrm{nM}, 100 \mathrm{nM}$, and $1000 \mathrm{nM}$.

Table S4. Interpolated values of organic carbon-normalized distribution coefficients coefficient $\left(K_{o c} \pm\right.$ $S D, L / \mathrm{kg}_{o c}$ ) of 9 representative PFASs in 5 soils. $K_{o c}=K_{d} / f_{o c}$, where $f_{o c}$ is the organic carbon fraction.

\begin{tabular}{|l|l|l|l|l|l|}
\hline & \multicolumn{1}{|c|}{ Soil } & $f_{o c}(\%)$ & $\mathrm{C}_{\mathrm{aq}}=10 \mathrm{nM}$ & $\mathrm{C}_{\mathrm{aq}}=100 \mathrm{nM}$ & $\mathrm{C}_{\mathrm{aq}}=1000 \mathrm{nM}$ \\
\hline 6:2 FTSA & Soil 1 - Loam & 3.4 & $181.9(29.3)$ & $77.6(25.0)$ & $33.1(16.0)$ \\
\hline $8: 2$ FTSA & Soil 1 - Loam & 3.4 & $183.7(42.3)$ & $96.4(44.4)$ & $50.6(34.9)$ \\
\hline PFOA & Soil 1 - Loam & 3.4 & $112.9(26.0)$ & $83.7(38.6)$ & $62.1(42.9)$ \\
\hline PFDA & Soil 1 - Loam & 3.4 & $308.2(63.9)$ & $256.4(106.3)$ & $213.3(132.6)$ \\
\hline PFOS & Soil 1 - Loam & 3.4 & $473.0(108.9)$ & $358.8(165.2)$ & $272.2(188.0)$ \\
\hline 6:2 FTAB & Soil 1 - Loam & 3.4 & $37.2(8.6)$ & $87.3(40.2)$ & $204.6(141.3)$ \\
\hline PFOAB & Soil 1 - Loam & 3.4 & $25.7(5.9)$ & $66.1(30.4)$ & $169.8(117.3)$ \\
\hline PFOSB & Soil 1 - Loam & 3.4 & $17.5(4.0)$ & $65.0(29.9)$ & $241.3(166.7)$ \\
\hline PFOAAmS & Soil 1 - Loam & 3.4 & $353.2(81.3)$ & $613.8(282.6)$ & $1066.6(336.8)$ \\
\hline
\end{tabular}




\begin{tabular}{|c|c|c|c|c|c|}
\hline $6: 2$ FTSA & Soil 2 - Clay loam & 1.7 & $85.3(5.9)$ & $117.7(16.3)$ & $162.5(33.7)$ \\
\hline $8: 2$ FTSA & Soil 2 - Clay loam & 1.7 & $210.6(24.2)$ & $156.1(36.0)$ & $115.7(40.0)$ \\
\hline PFOA & Soil 2 - Clay loam & 1.7 & $171.2(39.4)$ & $179.3(42.6)$ & $187.8(69.7)$ \\
\hline PFDA & Soil 2 - Clay loam & 1.7 & $211.8(48.8)$ & $359.7(165.6)$ & $610.8(421.9)$ \\
\hline PFOS & Soil 2 - Clay loam & 1.7 & $931.9(42.9)$ & $500.5(46.1)$ & $268.8(37.1)$ \\
\hline 6:2 FTAB & Soil 2 - Clay loam & 1.7 & $565.4(117.2)$ & $527.7(218.7)$ & $492.5(306.2)$ \\
\hline PFOAB & Soil 2 - Clay loam & 1.7 & $270.2(56.0)$ & $310.2(128.6)$ & $356.1(221.4)$ \\
\hline PFOSB & Soil 2 - Clay loam & 1.7 & $225.9(46.8)$ & $392.6(162.7)$ & $682.2(424.2)$ \\
\hline PFOAAmS & Soil 2 - Clay loam & 1.7 & $1915.3(396.9)$ & $2524.9(646.5)$ & $3328.5(869.3)$ \\
\hline 6:2 FTSA & Soil 3 - Silty clay loam & 2.9 & $105.7(7.3)$ & $124.2(17.2)$ & $146.0(30.2)$ \\
\hline $8: 2$ FTSA & Soil 3 - Silty clay loam & 2.9 & $206.9(47.6)$ & $221.7(102.1)$ & $237.6(164.1)$ \\
\hline PFOA & Soil 3 - Silty clay loam & 2.9 & $288.8(66.5)$ & $174.0(80.1)$ & $104.9(72.4)$ \\
\hline PFDA & Soil 3 - Silty clay loam & 2.9 & $571.6(144.8)$ & $584.9(296.3)$ & $598.6(454.8)$ \\
\hline PFOS & Soil 3 - Silty clay loam & 2.9 & $548.7(75.8)$ & $425.9(117.7)$ & $330.6(137.0)$ \\
\hline $6: 2$ FTAB & Soil 3 - Silty clay loam & 2.9 & $147.6(30.6)$ & $233.9(96.9)$ & $370.7(230.4)$ \\
\hline PFOAB & Soil 3 - Silty clay loam & 2.9 & $165.0(38.0)$ & $198.4(91.4)$ & $238.5(164.7)$ \\
\hline PFOSB & Soil 3 - Silty clay loam & 2.9 & $2972.6(821.3)$ & $1489.8(823.3)$ & 746.7 (618.9) \\
\hline PFOAAmS & Soil 3 - Silty clay loam & 2.9 & $2782.8(640.8)$ & $3051.3(905.2)$ & $3345.6(1011.1)$ \\
\hline $6: 2$ FTSA & Soil 4 - Loam & 7.3 & $83.2(23.0)$ & $100.0(55.3)$ & $120.2(99.7)$ \\
\hline $8: 2$ FTSA & Soil 4 - Loam & 7.3 & $157.6(29.0)$ & $352.9(130.0)$ & $790.0(436.6)$ \\
\hline PFOA & Soil 4 - Loam & 7.3 & $276.9(44.6)$ & $200.6(64.7)$ & $145.3(70.3)$ \\
\hline PFDA & Soil 4 - Loam & 7.3 & $697.1(176.6)$ & $898.0(454.9)$ & $1156.8(879.0)$ \\
\hline PFOS & Soil 4 - Loam & 7.3 & $760.9(175.2)$ & $914.8(421.3)$ & $1099.8(759.7)$ \\
\hline $6: 2$ FTAB & Soil 4 - Loam & 7.3 & $111.8(25.7)$ & $177.2(81.6)$ & $280.9(194.0)$ \\
\hline PFOAB & Soil 4 - Loam & 7.3 & $96.2(22.1)$ & $135.8(62.6)$ & $191.9(132.5)$ \\
\hline PFOSB & Soil 4 - Loam & 7.3 & $1069.3(246.2)$ & $388.3(178.8)$ & $141.0(97.4)$ \\
\hline PFOAAmS & Soil 4 - Loam & 7.3 & $551.9(127.1)$ & 694.7 (319.9) & $874.6(604.2)$ \\
\hline 6:2 FTSA & Soil 5 - Sandy loam & 1.8 & $14.7(1.4)$ & $30.1(5.5)$ & $61.5(17.0)$ \\
\hline $8: 2$ FTSA & Soil 5 - Sandy loam & 1.8 & $282.7(32.5)$ & $408.6(94.1)$ & $590.6(204.0)$ \\
\hline PFOA & Soil 5 - Sandy loam & 1.8 & $27.0(2.5)$ & $47.0(8.7)$ & $81.6(22.6)$ \\
\hline PFDA & Soil 5 - Sandy loam & 1.8 & $506.1(116.5)$ & $667.1(307.2)$ & $879.4(607.5)$ \\
\hline PFOS & Soil 5 - Sandy loam & 1.8 & $536.9(105.1)$ & $524.7(205.4)$ & $512.8(301.1)$ \\
\hline $6: 2$ FTAB & Soil 5 - Sandy loam & 1.8 & $305.6(56.3)$ & $216.3(79.7)$ & $153.2(84.6)$ \\
\hline PFOAB & Soil 5 - Sandy loam & 1.8 & $106.2(24.5)$ & $140.0(64.5)$ & $184.5(127.5)$ \\
\hline PFOSB & Soil 5 - Sandy loam & 1.8 & $171.2(23.6)$ & $333.7(92.2)$ & $650.7(269.7)$ \\
\hline PFOAAmS & Soil 5 - Sandy loam & 1.8 & $1555.5(250.7)$ & $1418.6(457.3)$ & $1293.8(625.6)$ \\
\hline
\end{tabular}




\section{SI-10. Relationship between $K_{d}$ and properties of soils.}

Table S5. Results of Pearson correlation between the adsorption distribution coefficient $\left(K_{d}\right)$ of PFASs and organic carbon fraction $\left(f_{o c}\right)$, clay fraction $\left(f_{\text {clay }}\right)$, cation exchange capacity (CEC), and anion exchange capacity (AEC)

\begin{tabular}{|c|c|c|c|c|c|c|c|c|c|c|}
\hline \multicolumn{2}{|c|}{} & \multicolumn{9}{|c|}{$K_{d}$} \\
\cline { 3 - 11 } \multicolumn{2}{|c|}{} & PFOA & PFDA & PFOS & $6: 2$ FTSA & $8: 2$ FTSA & $6: 2$ FTAB & PFOAAmS & PFOAB & PFOSB \\
\hline \multirow{2}{*}{$f_{\text {oc }}$} & $\rho$ & $\mathbf{0 . 9 5 6}$ & $\mathbf{0 . 9 5 1}$ & $\mathbf{0 . 9 6 7}$ & $\mathbf{0 . 9 5 1}$ & $\mathbf{0 . 9 1 9}$ & 0.675 & 0.143 & 0.787 & 0.408 \\
\cline { 2 - 11 } & Sig. & $\mathbf{0 . 0 1 1 ^ { * }}$ & $\mathbf{0 . 0 1 3 *}$ & $\mathbf{0 . 0 0 7 *}$ & $\mathbf{0 . 0 1 3 *}$ & $\mathbf{0 . 0 2 7 *}$ & 0.211 & 0.818 & 0.114 & 0.495 \\
\hline \multirow{2}{*}{$f_{\text {clay }}$} & $\rho$ & -0.677 & -0.623 & -0.713 & -0.711 & -0.570 & -0.402 & 0.283 & -0.439 & 0.092 \\
\cline { 2 - 12 } & Sig. & 0.209 & 0.262 & 0.177 & 0.178 & 0.316 & 0.502 & 0.644 & 0.460 & 0.883 \\
\hline \multirow{2}{*}{ CEC } & $\rho$ & -0.697 & -0.584 & -0.663 & -0.661 & -0.532 & -0.933 & 0.092 & -0.783 & 0.056 \\
\cline { 2 - 12 } & Sig. & 0.303 & 0.416 & 0.337 & 0.339 & 0.468 & 0.067 & 0.908 & 0.217 & 0.944 \\
\hline \multirow{2}{*}{ AEC } & $\rho$ & 0.802 & 0.815 & 0.872 & 0.712 & 0.815 & 0.856 & -0.335 & 0.766 & -0.122 \\
\cline { 2 - 11 } & Sig. & 0.198 & 0.185 & 0.128 & 0.288 & 0.185 & 0.144 & 0.665 & 0.234 & 0.878 \\
\hline
\end{tabular}

*A significance value (sig.) $<0.05$ is considered statistically significant $\left(95 \%\right.$ confidence level). $K_{d}$ was calculated at $\mathrm{C}_{\mathrm{aq}}=100 \mathrm{nM}$. Correlations analysis was done using SPSS (Version 25, IBM). 

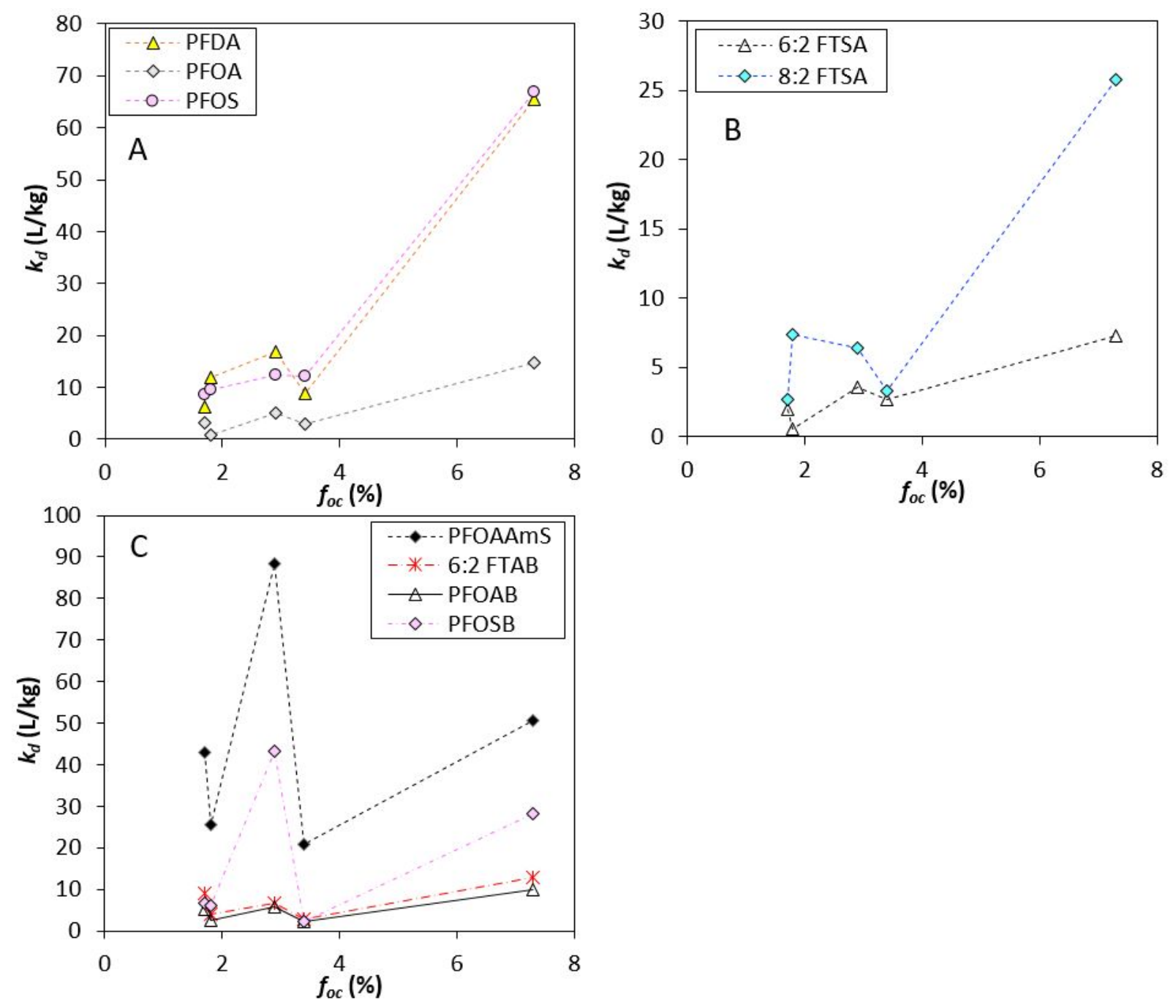

Figure S10. Relationship between $K_{d}$ of (A) perfluoroalkyl acids, (B) fluorotelomer sulfonates, and (C) newly-identified PFASs (i.e., 6:2 FTAB, PFOAB, PFOSB and PFOAAmS) and organic carbon fraction $\left(f_{c}\right)$ of soil. $K_{d}$ was calculated at $\mathrm{C}_{\mathrm{aq}}=100 \mathrm{nM}$. 

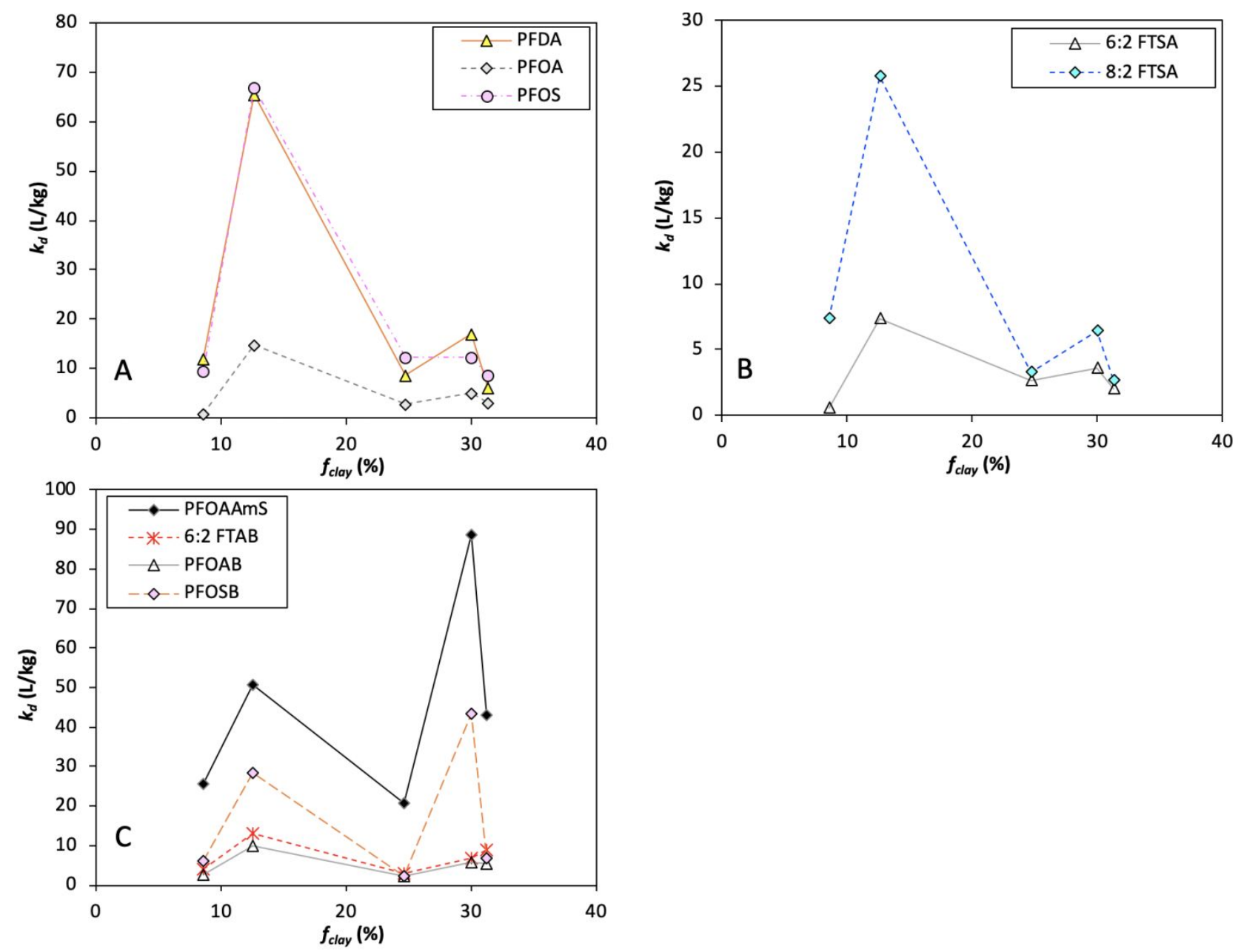

Figure S11. Relationship between $K_{d}$ of (A) perfluoroalkyl acids, (B) fluorotelomer sulfonates, and (C) newly-identified PFASs (i.e., 6:2 FTAB, PFOAB, PFOSB and PFOAAmS) and soil clay fraction $\left(f_{\text {clay }}\right)$. $K_{d}$ was calculated at $\mathrm{C}_{\mathrm{aq}}=100 \mathrm{nM}$. 

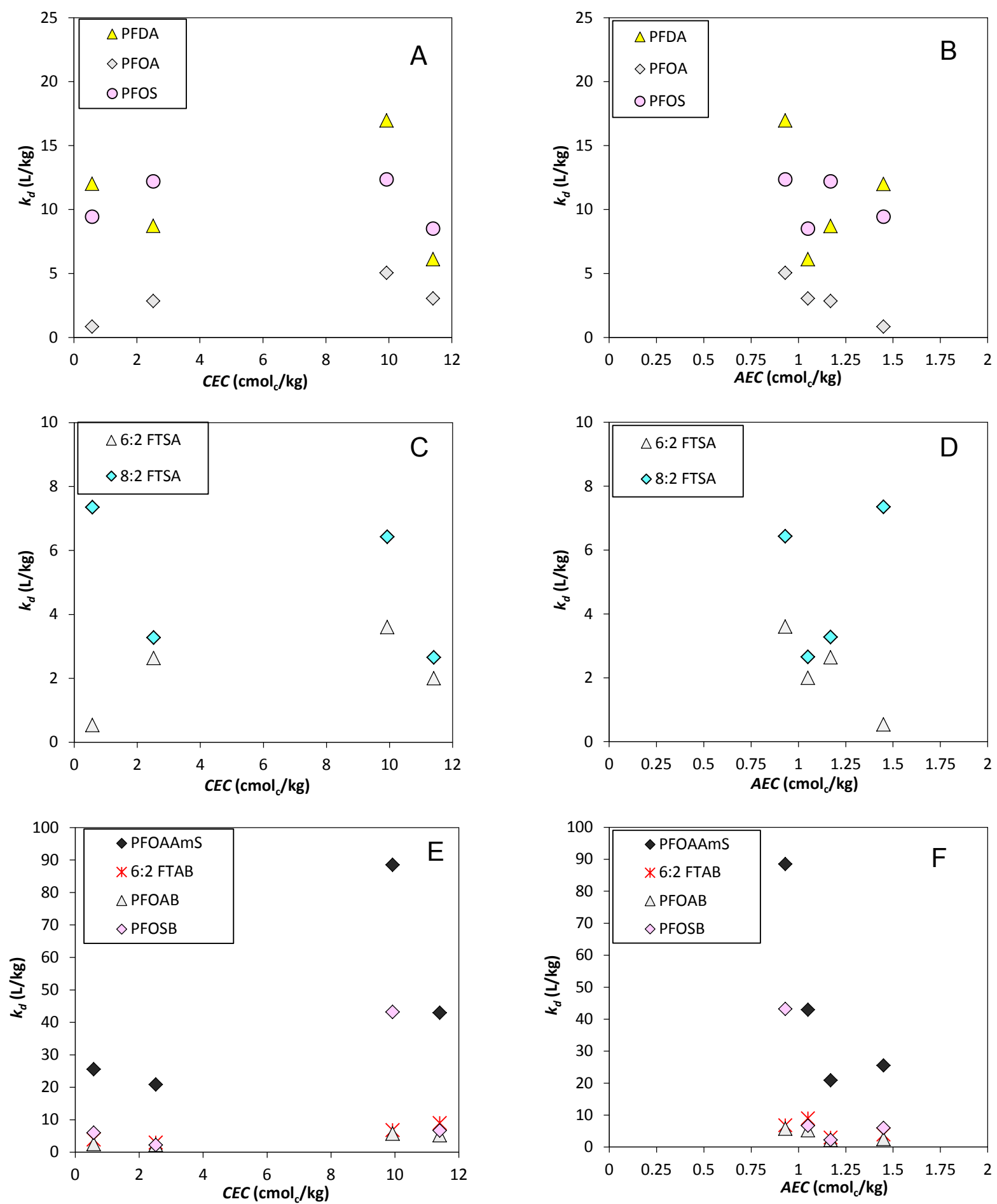

Figure S12. Relationship between $K_{d}$ of PFASs and soil cation exchange capacity (CEC), the left figures, and anion exchange capacity (AEC), the right figures. $K_{d}$ was calculated at $\mathrm{C}_{\mathrm{aq}}=100 \mathrm{nM}$. 


\section{References}

(1) Mejia-Avendaño, S.; Munoz, G.; Sauvé, S.; Liu, J. Assessment of the Influence of Soil Characteristics and Hydrocarbon Fuel Cocontamination on the Solvent Extraction of Perfluoroalkyl and Polyfluoroalkyl Substances. Anal. Chem. 2017, 89 (4), 2539-2546.

(2) Sumner, M. E.; Miller, W. P. Cation Exchange Capacity and Exchange Coefficients. Methods Soil Anal. part 3-chemical methods 1996, 1201-1229.

(3) Higgins, C. P.; Luthy, R. G. Sorption of Perfluorinated Surfactants on Sediments. Environ. Sci. Technol. 2006, 40 (23), 7251-7256. 